\title{
A Feral Atlas for the Anthropocene: An Interview with Anna L. Tsing
}

\author{
Anna L. Tsing and Jesse Bazzul
}

Jesse Bazzul: Thanks for agreeing to do this interview. One of our goals for the book is to get educators thinking differently about this peculiar and urgent time many are calling the Anthropocene-which for us means thinking differently about science, pedagogy, kinship, nonhumans, and politics. Your work has been inspiring for many people across education because it engages diverse forms of collective life in the hopes of reimagining the future. I wonder if you could talk about how you see this moment of the Anthropocene and perhaps how it changes how researchers and educators engage their work.

Anna Tsing: For me, the biggest challenge of trying to tell students about the Anthropocene, and tell the public in general, is that we have to learn new ways to tell stories that are simultaneously about human histories, and also about histories of the natural world. Because of the way particular structures of knowledge have dominated the last several centuries, people have managed to separate these histories. The result is that there are particular ways of storytelling about humans, and then there are wholly different ways of storytelling about plants and animals, or rocks and climate, and we don't know how to mix these up very well. They have different genres, different expectations, and so most of the time we tell stories about humans as if we humans lived in a

\author{
A. L. Tsing $(\bowtie)$ \\ University of California Santa Cruz, Santa Cruz, CA, USA \\ e-mail: atsing@ucsc.edu \\ J. Bazzul \\ University of Regina, Regina, SK, Canada \\ e-mail: jesse.bazzul@uregina.ca \\ (C) The Author(s) 2022
}


vacuum. And, in the same way, when we tell stories about plants and animals, or rocks and climate, it's as if they lived without humans. So somehow, the challenge of the Anthropocene is to figure out how to bring these ways of understanding the world together.

Jesse: In your book, The Mushroom at the End of the World: On the Possibility of Life in Capitalist Ruins, you talk a lot about different ways of noticing. And now you're currently working on another transdisciplinary project with colleagues at Aarhus University called Feral Atlas, where you're trying to illuminate different ways of telling stories and new storytelling techniques. I wonder if you can tell us a little bit about what Feral Atlas is about, and why such a project is urgent?

Anna: It's great to talk about this project in the context of science education because it's meant as a project of science education through the Anthropocene. That's the purpose of it.

Feral Atlas is an online digital platform for stories about the Anthropocene, which I'm putting together with many colleagues, like Jennifer Deger, Alder Keleman, Feifei Zhou and others, who are co-editors or curators of this project. In addition, we have something like 75 natural scientists, social scientists, artists, writers, and many other kinds of people contributing to it, in order to tell particular stories about the Anthropocene. None of these people or stories, however, tell the story of the Anthropocene as a whole. Instead, we have argued that one way to get a better grip on what's going on around us is to tell granular stories of the feral effects of the Anthropocene, understood as a spatial and temporal phenomenon. We felt like this would better attend to the kinds of questions of social justice on one hand-the uneven distribution of resources and forms of violence around us - and on the other, the natural phenomena relevant to the natural sciences emerging around us. So, for example, we have an entry on carbon dioxide, but not on a planetary scale all at once, but in terms of its particular effects. Coral reefs, for example, have been very sensitive to temporary changes, and so a key story of the Anthropocene is about the bleaching of coral reefs and their decreasing ability to support vast ecosystems because of the warming of the oceans, etc. In other words, parsing out the Anthropocene to the places where substantial differences can now be sensed, observed, and imagined, we argue, necessitates the skills that both the humanities on one hand, and natural scientists on the other, bring to us in order to think about the Anthropocene.

Jesse: And perhaps you could also clarify what you mean by feral... or ferality. In this case, it is in relation to various human infrastructures, yes?

Anna: Yes, let me backup for a minute to explain what both "feral" and "atlas" mean here. Designing the project, we decided to begin with the kind of human infrastructures that have been built for imperial conquest on one hand, and industrial development on the other, and how these infrastructures have created Anthropocene effects. Which were not the effects they were necessarily supposed to have! The word unintentional, however, would not be entirely accurate-because in many cases infrastructural designers knew perfectly well that they would have effects that weren't the ones that they designed for! In many cases, designers didn't seem to care about the fact that certain infrastructure projects were going to have these "extra" effects. Feral is a term that we have employed and stretched to talk about the ways that living beings, as 
well as non-living beings, react to the kinds of infrastructural projects humans come up with. So ordinary things like roads, nuclear power plants, and the burning of fossil fuels have effects beyond those that they were designed and promoted as having, and that's the feral role that we want to tell people about. And we call it an atlas because we're trying to pay attention to the particular places that matter. So, for example, carbon dioxide produced by fossil fuel burning happens in northern industrial centers, and only after a few days drifts around the world. We always tend to think of carbon dioxide as a planetary phenomenon because of how it's often measured, but it comes from particular locations and is chemically reduced in particular forests and other places. So, Feral Atlas is arguing that we need to think about the Anthropocene in patchy ways... an Anthropocene that's socially and environmentally uneven.

Jesse: I wanted to ask you about this, because I find the mapping part of the project very interesting. It seems to coincide with an increasing focus on, and a need for, topologies of environmental problems, political issues, and material realities. One of the things I came across in reading about Feral Atlas was that you utilize a map that disrupts scale and temporality and size. So, it's not a map like a google map of the planet, made by satellite imaging. Rather, it's a sort of disparate, forever ranging kind of map. I wonder what your thoughts are around the use of these maps for transdisciplinary work: how does this mapping project bring scientists and artists and humanities scholars together?

Anna: I think everyone expects a digital project that involves mapping to use GIS systems and to make everything commensurate so that it all builds up to one planetary map, and we've refused that from the very beginning. So, while there will be some completely recognizable maps in Feral Atlas, there'll be many that are at scales that are just incompatible with GIS systems. You see, some of the maps are just at a very small scale. For example, we have an entry on the scaly side of a salmon fish; which is about salmon farming and the subsequent death of a lot of wild salmon. And the scale here is incompatible on purpose. Another example of what we're calling a map, is a painting by an aboriginal artist from northern Australia, who has shown his people's relation to land and country through a painting of goanna lizards, or what we in the United States call monitor lizards, that have disappeared because of the introduction of the cane toad, which killed off many animals in northern Australia. And so, for him, showing that his people are celebrating the goanna lizards, even though they've disappeared from the area, along with the menace of the cane toads, is a map. We want to include this kind of first-hand empirical knowledge of a place, and in a different set of conventions than might otherwise be included in an atlas. So, we're purposely pushing the meaning of map in an atlas.

Jesse: I like this idea of patchiness, because it introduces a different way of viewing the world ontologically speaking. So, on an ethical level what does patchiness afford us?

Anna: An anthropologist named Eduardo Vivieros De Castro has made an argument for what he calls ontological anarchy, that is, imagining the world as having many kinds of ontological gaps that all work across each other at the same time. And, in a sense, I deem that to be quite useful as an approach to understanding the kinds of empirical knowledge we're going to need to understand the Anthropocene. Feral Atlas sometimes juxtaposes completely different ways of knowing and living in a world with Anthropocene creatures. 
For example, we have a woman's memoir about how important elm trees were to her growing up in the UK. They defined the boundaries and contours of her family's farmland, as well as created a sense of locality. Then Dutch Elm Disease arrived in the early twentieth century, and they had to kill and burn all of their elm trees. And this really changed her sense of self. And so, we juxtapose that narrative with a scientific article by a natural scientist, who is a plant pathologist studying how that incredibly virulent strain of Dutch Elm Disease, which again came and killed all the trees in the UK, was formed in part through hybridization practices of the commercial nursery trade at the time. So, the industrial infrastructure here is this concentration of the nursery trade in a few places, which has created and has allowed the emergence of so many new plant diseases that have then spread to new places around the world. So, we put these two perspectives on Dutch Elm Disease together side by side, while not forcing them to talk to each other directly. In doing so, we can see how perhaps, different kinds of immersion, knowledge, and ways of being might come up against each other in helping us with the Anthropocene. That is, in knowing what the Anthropocene is all about.

Jesse: One of the things that's impressive about the project is the bringing together of natural scientists, humanities scholars, and artists, etc. I am sure you understand the tensions that come up with transdisciplinary work especially. For example, on one hand scientists will say, "Ah, this isn't scientific enough." and a humanities scholar might say, "Well, your scientificity misses much of the point. "Your introduction to Feral Atlas encourages scientists, and all participants, to stay true to their training. So you encourage people to talk across boundaries, while allowing them to be true to what they know best. I think this is a really important point for educators trying to bring different kinds of people, ways of knowing, and disciplines together. I wonder if you could talk a little about your experience in bringing diverse people together.

Anna: Yes, well maybe a place to begin is by saying that the first question some contributors to Feral Atlas had was, "Please send me a model, a template." We've been very cautious, because we want the natural scientists to write like natural scientists, and we want the artists not to be illustrating science but rather bringing their vision and the way that they particularly understand things to the project. The last thing we want is to homogenize all the entries, because epistemological and ontological juxtapositions are at the heart of Feral Atlas... and I think science education for the Anthropocene.

Another way of putting it is that there is a need to enlarge what the term natural history has meant. Too often it is understood as a European-Colonial kind of practice that involved conquering the rest of the world, such that the term has connotations only of conquest. Yet, if you imagine natural history as everybody's vernacular engagement with the natural world around them, along with all the kinds of things they could observe and pay attention to, then there are many, many kinds of natural history. And although these kinds of natural histories may involve different conventions of knowledge, that doesn't mean they are not empirical. So, I believe that to get better understandings of the Anthropocene, we're going to need all different kinds of natural history. So, starting out with a set of regulations, and saying we will only accept work that meets these kinds of standards, means we lose the possibility of learning many different kinds of knowledge that are important for understanding the world 
around us. I would be really delighted if new kinds of research projects come out of the imagination that Feral Atlas is trying to put forward! Projects that start to blend different ways of thinking, the methods and skills of natural scientists on the one hand and social scientists, humanists, artists, etc. on the other. And I am very much hoping that segregation does not have to be the fate of these really contingent disciplinary silos, but instead, by beginning with their integrity, we might be able to see diverse projects going forward that make use of the talents on all sides.

Jesse: In our email exchanges you mention different kinds of media, and we may have touched on that a little bit at the beginning. What kinds of media and communication does Feral Atlas draw attention to, and how does it attempt to innovate on that level?

Anna: In some sense the timing is wrong for this question, because by the time the interview comes out, we might have designed everything differently. This is what's wrong with conversations in general. They are always meant for a particular moment!

Jesse: Haha, that's true! Whatever you say in this interview is going to be read after Feral Atlas is officially launched, and the final decisions already made about media formats, and things like that.

Anna: Well, Feral Atlas is trying very hard to make use of what digital media can do for us in terms of having a system for working across the different reports and essays. This digital media system involves all of the pleasures of the visual, as well as provoking people's curiosity. For example, Feifei Zhou is an architect who has drawn four magnificent landscapes that show what we call Anthropocene Detonators; which involve examination of the historical contingencies from which infrastructure projects have come into being. So, a user on Feral Atlas will begin by focussing their attention on a feral entity on these landscapes that depict Anthropocenic Detonators. They can then explore the landscape by looking around, or they can follow the little thing that they picked at the beginning and use the digital functions of being able to zoom in, zoom out on these landscapes. This, in turn, takes them to a set of musings about what human infrastructures are, and how they change the world. Also, a set of short videos being made for Feral Atlas will try to orient viewers to the way that infrastructures change the world by immersing viewers in a particular context and location, and emphasizing the gap between what we knew before and what we know now. And only then do they get to go and read documentation about this phenomenon. This documentation will draw attention to what we call feral qualities; which are the ways that nonhumans somehow gain purchase with these infrastructures, transform themselves, and become something different. Furthermore, at each of these analytic axes users have a chance to think about other entries in Feral Atlas that they might want to look at. Thereby creating comparisons or contrasts across entries. We are aiming to engage users, so that it's not just a reading project. In fact, Feral Atlas bears a notable resemblance to games, art projects, and research archives due to the possibilities afforded by new digital formats.

Jesse: I think it's very curious that you've specifically chosen to talk about infrastructure from a human perspective, as infrastructure can mean many different things to different people. So instead of a media studies, or nonhuman perspective, of infrastructure you specifically look at infrastructures designed 
and built by humans. It seems that you and your colleagues are doing this in order to inject a much needed political context for the project. I am reminded of your earlier work where you focus on feral outcroppings created by political-ecological disturbances. One of the things that seems to be true of our current moment in time, is that it is impossible to live outside of things like capitalism and human infrastructures. I feel that, just like with Mushroom at the End of the World, Feral Atlas demonstrates the need for finding new forms of collectivity in the ruins of human infrastructures and capitalism. So I am wondering if you could speak a little bit about the political urgency in which this project unfolds.

Anna: There's a lot bundled together there, so let's begin with the infrastructure question. For me, one of the reasons to focus on these human-kind of infrastructures is that, rather than the Anthropocene being a kind of planetary or abstract-nothing situation, we would like to ground our understanding of what's going on with particular entities. So, for example, if it's a railroad, and it stretches quite a long way, and we can see that the railroad has created certain effects, then it should give people pause the next time someone wants to build a railroad in that particular way!

Part of the conceit of modernity, since at least the middle of the nineteenth century, is that there would be no regrets. That you would build all of this stuff and it would only lead to a brighter world, and that you just didn't have to pay attention to what else was going on around you, what else might emerge from these things that were being built. So, infrastructure was designed, built, and installed without a care. It's not that people didn't know that if you put in a nuclear reactor, radiation was going to get out and become part of the metabolism of plants and animals, including humans. Everybody knew that. But they thought, who cares, it's a great idea! The engineers are going to make it happen, it's a wonderful thing! Look, wow, you can put corn chips in bags! Nobody thinks ok, where's that plastic going to go and how many marine mammals are going to subsequently die? So it's these kinds of issues that have not been on the radar. To me, one really important part of science education in the Anthropocene is that people think about these kinds of infrastructural projects that all of us bring ourselves into every day. Many of which really are unnecessary. I can't think of any reason why styrofoam is allowed to be manufactured at all, but it lasts pretty much forever. So I'm hoping that the students that science educators influence, that we all influence as educators, might be able to think about these infrastructural projects and say: "You know, there are some that we really could do more thoughtfully and carefully... perhaps not at all."

Jesse: I want to dwell a little on the concept of disturbance in your work overall. In Mushroom at the End of the World you note that ecological succession patterns of human-designed environments sometimes don't follow the typical categories of succession in the biological sciences. You also show similarities between psychic disturbance and ecological disturbance. Namely that... once disturbed life patterns change. Some disturbances, as you show, can be ambiguous - a volcano can be a disturbance and so could a traumatic event. If the Anthropocene involves learning to live with disturbance, what might an ethics of disturbance look like? 
Anna: Ah, you've just identified, I think, a big ethical question, which is: which kinds of human disturbances are we willing to live with? And which kinds are we not willing to live with? And I think this is where the term Anthropocene can help us. One of my colleagues, Zachary Caple, has introduced the term Holocene fragments. I mean, he's really spacialized what constitutes the Holocene and what constitutes the Anthropocene. He uses the term Holocene, which you know was only less than 12,000 years ago, being cognizant that humans were very much a part of the Holocene. Farming was part of the Holocene, the trade and travel of humans was also part of the Holocene, and so what is left of the Holocene still exists in fragments. I'm sorry, I'm sort of mixing up the order this should be introduced...

A Holocene fragment is basically an ecological space in which mutualisms and complementarities of various sorts, often having ecologically foundational moralities or moral terms, continue to exist. Caple's example is the Florida scrubland, where a particular kind of bird feeds on a particular kind of acorn from a particular kind of oak. And, that it's these kinds of specific long-term arrangements between birds and trees that actually allows the scrubland to exist in the first place! And so he compares these Holocene fragments to Anthropocene landscapes like the ecological disturbance caused by a Florida phosphorus mine, along with the attempts to cover up this disturbance. For example, just simply rolling grass out on top of the barren clay landscape created by the mine! This is what Caple calls an Anthropocene landscape, and in his work he richly describes an area where you have a long stretch of fencing, where on the one side you have this scrub forest, and on the other you have this rolled out turf? And in a sense, they're both forms of nature. Since you asked the ethical question, we should be able to distinguish between those two kinds of natural environments around us. Perhaps holding on to the Holocene fragments that we already have is a major ethical commitment that we might want to make as more and more landscapes get transformed into these uninhabitable landscapes; not just for humans, but for all of our nonhuman living companions too.

So, I think what you're saying is right, that there's an ethical challenge in distinguishing the kind of disturbances that work more toward different kinds of flourishing. Perhaps then it is a good time to turn to the feral, in that we need to attune to the nonhuman response to the way humans are living. Again, that's when a field is allowed to go back to forest; the trees growing and replacing a highly specific human-created environment. That's the feraland it's absolutely necessary to the worlds we live in. We can't do without it. Yet, at the same time, we have to learn that some kinds of ferality are not okay.

Jesse: So looking to ferality could also be where we somehow begin to explore an ethics. It is a very exciting question, because ethics would include a differentiation between ecologies, what might have been more consistent to the Holocene without destructive human interventions versus these Anthropocene landscapes. It might also then mean looking to flourishing, or non-flourishing, as a kind of ethical substance. For me, this seems like a really important ethical project. 
Anna: I have also started to think of these things affectively in terms of wandering mists of dread. It's really important to acknowledge the severity of the environmental challenges in front of us, while remaining appreciative of all that feral action around us. To try and access it with all our skills and curiosity and passion, in order to have a sense of what we can and want to live with.

Jesse: Education and anti-capitalist movements haven't been the best partners historically-and what I get from your work is that we are going to have to face or live with capitalism as a massive disturbance going forward. How must attention to capitalism be a part of the context for education, especially in and around the sciences, going forward?

Anna: Well, to begin with capitalism has brought us this really bad idea that very distanced investors, who don't care about places, can have full control over them and wreck them completely without suffering any consequences. That is a really bad idea! But, rather than starting at that abstract level, we could also talk about aspects of capitalism that are very new and very dangerous, but are already treated as if they're set in stone and you could never change them! Take the example of drug derivatives, and the destruction of many different communities by things like opioid addiction. However, again, this phenomenon relies on these distant pharmaceutical investors-who don't care about places - and yet the prevalence of these drugs has risen enormously in the last twenty to thirty years. And over and over again, a prevailing belief amongst scientists, scholars, journalists, and the general public is that we can't mess with free trade... as if it were some kind of sacred establishment! But what free trade often means is a complete lack of regulation of incredibly dangerous things, even when many kinds of precautions and procedures exist for controlling these dangerous things. For instance, I myself am really horrified by the fact that we allow soils to be sold and shipped large distances at an incredibly large rate and scale. The whole world already has well distributed soils! You don't need to move them around the world, yet we allow massive corporations to ship them everywhere, spreading plant diseases and endangering plants without ever really thinking about how dependent we are on those plants.

But, it has been one expansion of capitalism after another, and no-one really has, or has been allowed to, speak up about regulating things that are completely unnecessary for human health and destructive for the wellbeing of many other kinds of organisms. Just because of the so-called sacrosanct status of free trade, no one even discusses it!

Jesse: And so Feral Atlas becomes a challenge to destructive ideas of economic and ecological scalability. In your past work you examine specific places where capitalism is operating through detailed supply chains and ask what other forms of life are still possible despite these operations. Do you see resistance to the commodification of life involving a confrontation with capitalism's own sacred pillars like scalability and private property as the basis of law? Or is the historical point that things went drastically wrong much earlier? Say with the advent of colonialism. Are there also temporal distortions, as well as the spatial ones, you focus on in Feral Atlas?

Anna: Well, to be clear, Feral Atlas has some temporal questions woven into it.

So maybe I can answer by describing the four Anthropocene Detonators, or historical conjunctures, that have given shape to human infrastructure and give 
depth to the Feral Atlas project. The first detonator is Invasion. So we really begin with the invasion of the New World by Europeans. And the kinds of murder and displacement that happened, and the displacement and desecration of native ecologies and native peoples went together. And we don't say that just happened 500 years ago, because it is still happening in the present. Not only because indigenous people are still being displaced, like for example, in Australia, but also because of the continuing ways that colonialism as a set of institutions, world-making practices, and ideas continues to rule. For example, one of the Feral Atlas pieces is about the kinds of pasture grasses that were imported to the Amazon in order to purposely disallow the forest to grow back. Again, the feral at work! The forest can't grow back when these very aggressive pasture grasses are introduced and so the contributor talks about how people viewed them as a form of invasion. Certain people wanted this invasion, the conquest of the Amazon through grass, so that both the people who lived there and specific ecologies could no longer exist. So, the first Anthropocene detonator is Invasion.

Our second detonator is Empire, and we begin with European, and move into Asia, and deal with things like the triangular trade in which captive, kidnapped Africans were brought to do plantation labor in the New World. We emphasize that there are many forms of imperial conquest. So not just invasion, but the governance of people from afar created huge infrastructural programs involving water management, plantation agriculture, and all kinds of ways of channeling resources to imperial cities. And those things are all still with us. Part of what has happened since World War Two, and the partial decolonization of the Global South, is that these imperial infrastructure projects have been used by national elites all around the world, to continue the same kinds of water management and plantation agriculture systems-all of which were started some time ago. Thereby making that imperial mode of governance even more entrenched.

Our third detonator is Capital. Here, we begin in the nineteenth century with the interconnection between things like plantation agriculture, in which slavery was such an important part, and the burgeoning industrial development in the metropole. So altogether, how these things together create that whole world of capital, in which the rationalization of resources and commodities is spread around the world.

Our fourth detonator is called Acceleration, which relates to the great acceleration after World War Two: where Invasion, Empire, and Capital are brought to new heights. In part, this is because they were distributed around the world in a new way, such that all kinds of infrastructure building programs, however destructive, were marketed as the way to a better life. They were also marketed on the presupposition, which is entirely false, that all their waste products can go to some other place. And, of course, because of imperial programs writ large, there were those other places for waste to go unseen. But now, those other places are everywhere. Furthermore, the kinds of waste that got invented in the first half of the twentieth century, from radioactivity to plastics, have proved to be much more long-lasting, and much less able to be recycled, than what came before. We have a new set of landscapes created by these non-disposable wastes, and each of these create a landscape of injustice and mistreatment that just gets ever more dense. 
I think my biggest fears about the Anthropocene is that the gap between the super elite and disadvantaged will keep growing. As the elite try to find ways to shelter themselves from the toxins, waste, and death they've unleashed on the rest of the world, there is also a kind of densification of poverty, inequality, and deprivation.

Jesse: I wonder if you could share some of your experiences in trying to motivate people to take up the call to action and revisioning. As science educators, we talk to young people and students about environmental destruction a lot, but how might we bring people on board?

Anna: Well, as far as Feral Atlas is an educational project, some people have compared it a little bit with Rachel Carson's Silent Spring. The reason I find this comparison interesting is that when I was last reading about the history of DDT, and those terrible insecticides, what I learned was that DDT was one of our most well-studied toxins in the history of science. Even before Rachel Carson, there were hundreds of studies of DDT, and each one established levels of safety, rules of proper use, and concluded over and over again that if people used it safely enough DDT was just fine. What Rachel Carson did to blow that out of the water was start from a different place. Rather than think, well, could we simply adjust the levels a little bit? She asked, "What happened to the songbirds? Why did they all die?" So, sometimes a change in angle can get one to a new place, and I would like Feral Atlas to be a small part of a way of saying, "Okay, here's some things that can be addressed." Even specific things that can be addressed. So, for example, a scientist in Feral Atlas has written about the extinction of many kinds of Pacific tree snails, in part because of the purposeful distribution of a carnivorous snail, called the Rosy Wolf snail, that eats all the other tree snails. And on top of this, the Rosy Wolf snails are still being distributed to new Pacific islands where they're not yet part of any problems. At the very least we could stop that; and things like the distribution of live soils around the earth, as well as the continued use of styrofoam. You know, enough is enough!

Jesse: It seems that some things in our world are so "siloed" they really don't make sense anymore. Your work really tries to expose some of these vicious and strange aspects of the Anthropocene, so they can be seen in different ways. Teachers really cherish examples of how we might try doing things differently, because that's what we are trying to do in educational institutions every day.

Anna: Well, I hope you bring students outside of the classroom, to look around them. I think it's very easy to see many kinds of Anthropocene phenomena such as human infrastructure and feral action. Even sidewalks. The feral action part is when we notice the weeds that are coming out of the sidewalk, as well as the sidewalk itself. And students who have a chance to be observing these phenomena might become concerned and informed about how to think differently about these issues. I'm going to say one more thing because, you know, what school kids are doing right now is so exciting to me, around the world. I just got back from a conference in Ireland a little while ago and everybody was talking about the Swedish girl Greta [Thunberg] and the schools movement that she has stimulated globally. I hope science education for Anthropocene doesn't dampen the spirit of young people, but instead encourages them to think of creative interventions before it's too late. 
Jesse: Right. So, seeing human infrastructures and ferality as a kind of unraveled complex.

Anna: I also find this idea of ferality in young children. This difference between not noticing the sidewalk, but the grass growing in between the cracks of the sidewalk-it seems to me that children might be the best observers of this. Perhaps college students aren't much different. It is my dream to have students go out and identify, discuss, and perhaps intervene in feral entities in their communities and neighborhoods. Put a bit of themselves alongside these feral entities!

Jesse: Great idea! I think this might be a good place to end. Well, thank you so much for sharing today. I really appreciate it.

Anna: Yes, and thank you.

Open Access This chapter is licensed under the terms of the Creative Commons Attribution 4.0 International License (http://creativecommons.org/licenses/by/4.0/), which permits use, sharing, adaptation, distribution and reproduction in any medium or format, as long as you give appropriate credit to the original author(s) and the source, provide a link to the Creative Commons license and indicate if changes were made.

The images or other third party material in this chapter are included in the chapter's Creative Commons license, unless indicated otherwise in a credit line to the material. If material is not included in the chapter's Creative Commons license and your intended use is not permitted by statutory regulation or exceeds the permitted use, you will need to obtain permission directly from the copyright holder.

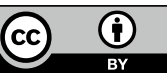

